\title{
KIDNEY FUNCTION, POLYPHARMACY, AND POTENTIALLY INAPPROPRIATE MEDICATION USE IN A COMMUNITY-BASED COHORT OF OLDER ADULTS
}

\author{
Alex Secora, MPH ${ }^{1,2,3}$, G. Caleb Alexander, MD MS ${ }^{1,3,4}$, Shoshana Ballew, $\mathrm{PhD}^{1,2}$, Josef \\ Coresh, MD PhD ${ }^{1,2}$, and Morgan Grams, MD PhD $1,2,3,5$
}

${ }^{1}$ Department of Epidemiology, Johns Hopkins Bloomberg School of Public Health, Baltimore, Maryland ${ }^{2}$ Welch Center for Prevention, Epidemiology and Clinical Research, Johns Hopkins Bloomberg School of Public Health, Baltimore, Maryland ${ }^{3}$ Center for Drug Safety and Effectiveness; Johns Hopkins Bloomberg School of Public Health; Baltimore, Maryland ${ }^{4}$ Division of General Internal Medicine; Department of Medicine; Johns Hopkins Medicine, Baltimore, Maryland ${ }^{5}$ Division of Nephrology; Department of Medicine; Johns Hopkins Medicine, Baltimore, Maryland

\begin{abstract}
Background-Chronic kidney disease (CKD) afflicts many older adults, and increases the risk for medication-related adverse events.

Objective-To assess the prevalence and associated morbidity and mortality of polypharmacy (use of several medications concurrently), and potentially inappropriate medication (PIM) use in older adults, looking for differences by CKD status.

Methods-We quantified medication and PIM use (from Beers criteria, the Screening Tool of Older People's Prescriptions, and Micromedex $\left.{ }^{\circledR}\right)$ by level of estimated glomerular filtration rate (eGFR) for participants 65 years or older attending a baseline study visit in the Atherosclerosis Risk in Communities study ( $\mathrm{N}=6,392)$. We used zero-inflated negative binomial and Cox
\end{abstract}

\footnotetext{
Correspondence: Alex Secora, Department of Epidemiology, Johns Hopkins Bloomberg School of Public Health 615 N. Wolfe Street, Baltimore, Maryland 21205, Phone: 917-355-3345, asecora1@jhu.edu.

Preliminary data from this study were presented in a spotlight poster session at the 33rd International Conference of Pharmacoepidemiology and Therapeutic Risk Management in Montreal, Canada, August 27-30, 2017.

COMPLIANCE WITH ETHICAL STANDARDS

Conflicts of interest:

Dr. Alexander is Chair of FDA's Peripheral and Central Nervous System Advisory, Committee, has served as a paid advisor to IQVIA, serves on the advisory board of, MesaRx Innovations, is a member of OptumRx's National P\&T Committee; and holds, equity in Monument Analytics, a health care consultancy whose clients include the life, sciences industry as well as plaintiffs in opioid litigation. This arrangement has been reviewed and approved by Johns Hopkins University in accordance with its conflict of interest policies. Alex Secora, G. Caleb Alexander, Shoshana Ballew, Josef Coresh and Morgan Grams declare that they have no conflicts of interest relevant to the content of, this study.

Author contributions:

Research idea and study design: Alex Secora, G. Caleb Alexander, Shoshana Ballew,, Josef Coresh, Morgan Grams; data analysis/ interpretation: Alex Secora, G. Caleb, Alexander, Shoshana Ballew, Josef Coresh, Morgan Grams; statistical analysis: Alex Secora, Morgan Grams; supervision or mentorship: G. Caleb Alexander, Josef Coresh,, Morgan Grams. Each author contributed meaningfully to manuscript content during its, preparation or revision, and accepts accountability for the overall work.
} 
proportional hazards regressions to assess the relationship between baseline polypharmacy, PIM use, and subsequent hospitalization and death.

Results-Mean age at baseline was $76( \pm 5)$ years, 59\% were female, and 29\% had CKD (eGFR $\left.<60 \mathrm{ml} / \mathrm{min} / 1.73 \mathrm{~m}^{2}\right)$. Overall, participants reported $6.1( \pm 3.5)$ medications and 2.3( \pm 2.2$)$ vitamins/ supplements; $16 \%$ reported $\geq 10$ medications; $31 \%$ reported a PIM based on their age. On average, participants with CKD reported more medications. A PIM based on kidney function was used by $36 \%$ of those with eGFR $<30 \mathrm{ml} / \mathrm{min} / 1.73 \mathrm{~m}^{2}$. Over a median of 2.6 years, more concurrent medications were associated with higher risk of hospitalization and death, but PIM use was not. While those with CKD had higher absolute risks, there was no difference in the relative risks associated with greater numbers of medications by CKD status.

Conclusion-Polypharmacy and PIM use were common, with greater numbers of medications associated with higher risk of hospitalization and death; relative risks were similar for those with and without CKD.

\section{INTRODUCTION}

Older adults constitute a vulnerable and growing segment of the population with a particularly high burden of comorbid conditions like chronic kidney disease (CKD), which affects up to $40 \%$ of older adults in the United States. $(1,2)$ As a consequence of more comorbidities, medication use in older adults is high, yet drug metabolism and clearance may change with age, especially in the setting of CKD. (3) Common in older adults, (4-10) polypharmacy has been linked to higher risk of adverse drug-drug interactions, $(4,5,7-9$, $11-14)$ and morbidity and mortality. $(11,15-23)$

Another medication-related risk factor that may be associated with morbidity and mortality in older adults, particularly those with CKD, is potentially inappropriate medication (PIM) use. $(11,22,24)$ Pharmacy and published medication references suggest that PIMs be avoided or carefully monitored in the setting of older age or CKD to mitigate preventable adverse effects. Certain drugs and drug metabolites are excreted by the kidney, necessitating dose adjustment or drug avoidance in those with reduced kidney function to prevent potentially toxic exposure levels. (25-28) Studies have suggested that PIM use based on level of kidney function is common, $(12,13,29-37)$ but not always recognized, $(7,12,13)$ with estimates as high as $62-67 \%$ in the inpatient and ambulatory setting. $(33,35)$ Moreover, medication resources for prescribers often present conflicting recommendations on appropriate renal-based dosing and contraindication, and have uncertain uptake in clinical practice. (38-42) Evaluating overall and specific medication use as potentially modifiable risk factors that might impact health outcomes in older adults is critical.

Several studies have evaluated the risk of hospitalization (17-20, 43) and death $(15,16,21$, 24, 43-51) associated with polypharmacy and PIM use in older populations, but these studies were limited by homogenous samples, cross-sectional study designs, lack of information on kidney function, or limited information on the use of over-the-counter medications. Therefore, we characterized baseline medication use across stages of kidney function in a community-based cohort of older adults, with a particular focus on medications deemed "potentially inappropriate" based on kidney function or age, by any one of three 
commonly used drug references: the Beers criteria, the Screening Tool of Older People's Prescriptions (STOPP) criteria, and Micromedex ${ }^{\circledR}$. We then quantified the subsequent risk of hospitalization and death among those with baseline PIM use and polypharmacy, and assessed for differences by CKD status.

\section{METHODS}

\subsection{Study population}

The Atherosclerosis Risk in Communities (ARIC) study is a long-standing, populationbased, prospective cohort study of 15,792 adults followed since 1987-1989. (52) In brief, ARIC study investigators recruited participants between 45 and 64 years of age in the United States from Forsyth County, North Carolina; Jackson, Mississippi; suburban Minneapolis, Minnesota; and Washington County, Maryland. For this prospective analysis, we included participants who attended ARIC study visit five (baseline visit), which took place between June, 2011, and August, 2013 ( $N=6,544)$. We excluded participants without a serum creatinine measurement at visit five $(\mathrm{n}=96)$, those with end-stage renal disease as defined by registration in the United States Renal Data System ( $\mathrm{n}=38$ ), and non-white/non-black participants $(\mathrm{n}=18)$ leaving a total study population of 6,392 participants (Electronic Supplementary Material Figure S1). ARIC had IRB approval at all study sites and participants gave informed consent at each visit.

\subsection{Measurement of kidney function and other covariates}

We defined kidney function by a participant's estimated glomerular filtration rate (eGFR). We calculated eGFR using serum creatinine (measured by the modified kinetic Jaffé method), and the equation developed by the Chronic Kidney Disease Epidemiology Collaboration. (53) We classified CKD into G-stages (G1 $=\geq 90 \mathrm{~mL} / \mathrm{min} / 1.73 \mathrm{~m}^{2} ; \mathrm{G} 2=60-89$ $\mathrm{mL} / \mathrm{min} / 1.73 \mathrm{~m}^{2} ; \mathrm{G} 3 \mathrm{a}=45-59 \mathrm{~mL} / \mathrm{min} / 1.73 \mathrm{~m}^{2} ; \mathrm{G} 3 \mathrm{~b}=30-44 \mathrm{~mL} / \mathrm{min} / 1.73 \mathrm{~m}^{2} ; \mathrm{G} 4=15-29$ $\mathrm{mL} / \mathrm{min} / 1.73 \mathrm{~m}^{2} ; \mathrm{G} 5=<15 \mathrm{~mL} / \mathrm{min} / 1.73 \mathrm{~m}^{2}$ ). (53) We also categorized participants by level of albuminuria using their urine albumin to urine creatinine ratio $(<30 \mathrm{mg} / \mathrm{g}, 30-300 \mathrm{mg} / \mathrm{g}$, $>300 \mathrm{mg} / \mathrm{g}$ ). We defined CKD as eGFR $<60 \mathrm{~mL} / \mathrm{min} / 1.73 \mathrm{~m}^{2}$ at visit five, without regard to CKD duration or level of albuminuria.

We defined diabetes mellitus as a self-reported diabetes diagnosis, or the use of glucose lowering medications in the previous 30 days, and hypertension as a blood pressure measure of systolic $\geq 150 \mathrm{~mm} \mathrm{Hg}$ and diastolic $\geq 90 \mathrm{~mm} \mathrm{Hg}$, or antihypertensive medication use during the previous 30 days. For blood pressure measurement, a certified technician collected three seated measurements using a random-zero sphygmomanometer after 5 minutes of rest, and the mean of the second and third readings was used. We defined heart failure by self-reported or physician-assessed heart failure, or prior physician-adjudicated heart failure. We defined cardiovascular disease as prevalent coronary artery disease or stroke. We ascertained myocardial infraction (MI) since participants' last ARIC visit using self-report. Similar to other ARIC investigations, (54) we defined frailty based on five criteria including weight loss, exhaustion, low energy expenditure, slowness, and weakness; in this analysis, pre-frail (1-2 criteria) and frail ( $\geq 3$ criteria) were combined. We calculated the Charlson Comorbidity Index $(\mathrm{CCI})(55,56)$ based on data from previous hospitalizations 
using abstracted hospital records that were obtained from data linkages with hospitals in the proximity of ARIC study sites, or record requests from hospitals outside of those areas. To ascertain cognitive functioning, we used the Mini-Mental State Examination (MMSE) questionnaire score. We derived body mass index (BMI) using weight (kilogram) and height (meter) measurements taken during physical examinations. We also captured low-density lipoprotein (LDL) cholesterol, high-density lipoprotein (HDL) cholesterol, and triglycerides from fasting blood samples drawn during physical examinations. All other variables, such as sex, race, age, current smoking status, and alcohol consumption (grams per week) were selfreported during a structured interview. All definitions were based on information collected at participants' visit five assessment.

\subsection{Medication use}

ARIC study staff captured prescription and over-the-counter (OTC) medication use, as well as vitamin and dietary supplement use, through structured interviews at visit five.

Participants brought all medications and other products they had used in the prior 30 days to their study visit. If the participant did not bring their medications, study staff followed-up over the phone to collect these data. Study staff recorded a maximum of 25 products. Thirtyeight participants $(0.6 \%)$ brought more than 25 products to their study visit; therefore, some product use on those participants was not collected. For the purpose of the current study, we did not count non-injectable solutions, creams/lotions, and devices as medications, leaving 554 unique medications.

\subsection{Medication references}

We categorized all 554 unique prescription and OTC oral, inhaled, or injectable medications by their drug grouping using the generic product identifier classification system. Since medication use information was obtained without regard to the method of attainment (prescription vs. OTC) or frequency of dosing (regular vs. as needed), we grouped all prescription and OTC nonsteroidal anti-inflammatory drugs (NSAIDs) into a combined NSAID category. We assessed medications in three commonly used drug references for older adults: American Geriatrics Society Beers 2015 criteria, (57) Screening Tool of Older People's Prescriptions (STOPP) version 2 criteria, (58) and Truven Health Analytics online pharmacy reference Micromedex ${ }^{\circledR} 1.0$ (Healthcare Series; electronic version; Greenwood, Colorado; accessed: August, 2016). We identified and cross-referenced medications that were contraindicated or recommended to avoid based on one's kidney function in any of the three references. We also identified and cross-referenced medications that were contraindicated based on one's age alone in Beers and STOPP only, as Micromedex ${ }^{\circledR}$ generally references Beers or STOPP criteria in its age-based recommendations.

Many medications in the Beers and Micromedex ${ }^{\circledR}$ references are noted as contraindicated according to creatinine clearance or glomerular filtration rate that is not adjusted for body surface area. In these instances, we converted the participant's eGFR to unadjusted units $(\mathrm{mL} / \mathrm{min})$ by multiplying the eGFR $\left(\mathrm{mL} / \mathrm{min} / 1.73 \mathrm{~m}^{2}\right)$ by their calculated body surface area divided by 1.73 , similar to other investigations. $(59,60)$ Where an absolute threshold was not explicitly stated but reference was made to avoid in "significant" or "severe" renal 
impairment, we a priori assumed an eGFR threshold of $<30 \mathrm{~mL} / \mathrm{min} / 1.73 \mathrm{~m}^{2}$; when only

"renal impairment" was noted, $<60 \mathrm{~mL} / \mathrm{min} / 1.73 \mathrm{~m}^{2}$ was used.

\subsection{Assessment of polypharmacy and PIM use}

We categorized polypharmacy using several categories of total number of prescription or OTC medications in the last 30 days, excluding the use of other products such as vitamins and supplements: 0-3 medications, 4-5 medications, 6-9 medications, and 10 or more medications. We defined kidney-based PIM use as the use of a medication that was contraindicated or recommended to avoid based on the participant's kidney function in any of the medication references. Because dose information was not available, PIM use based on dose was not assessed. We defined age-based PIM use as the use of a medication noted in Beers or STOPP as contraindicated in adults age 65 years or older; all participants included in this study were 65 years or older. We did not include contraindications based on two or more combined criteria such as contraindications based on one's age plus an existing condition, or the use of another medication concomitantly. Where references differed with respect to kidney function (i.e. Micromedex lists eGFR $<45 \mathrm{~mL} / \mathrm{min} / 1.73 \mathrm{~m}^{2}$, and STOPP lists eGFR $<30 \mathrm{~mL} / \mathrm{min} / 1.73 \mathrm{~m}^{2}$ for the same drug), we used the stricter criteria for analyses (i.e. eGFR $<45 \mathrm{~mL} / \mathrm{min} / 1.73 \mathrm{~m}^{2}$ ). In addition, given that we did not have start dates or duration of use, the use of a medication (e.g. metformin) was counted as potentially inappropriate in a participant if a drug reference recommended not starting the medication at their level of kidney function.

\subsection{Assessment of hospitalizations and death}

ARIC study staff monitor and abstract hospitalization data for ARIC cohort members through data linkages with local hospitals in proximity to each of the four ARIC sites; hospitalizations outside of the community area are identified through semi-annual participant reports, and subsequent record requests are made to obtain data from those hospitalizations. In this investigation, we included any hospitalization, regardless of the reason. Vital status was captured through linkages to the National Death Index. Participants' observation time began at their visit five (baseline visit/index date), and both hospitalizations and mortality were assessed through December 31, 2014, or participants' last known contact with study staff.

\subsection{Statistical analysis}

We calculated frequencies, means and proportions of cohort characteristics and medication use, including polypharmacy, kidney-based PIMs, and age-based PIMs, for all participants, stratified by CKD stage. We assessed trends across CKD G-stages in cohort characteristics, polypharmacy category, and mean number of medications and vitamins using logistic and linear regression for binary and continuous variables, respectively, and an ordinal CKD Gstage variable. We also used independent sample t-tests and two-sample tests of proportions to compare medication use between CKD and non-CKD participants. We tested for associations between mean number of medications and CKD stage using univariable and multivariable linear regressions. We also tested for associations between PIM use and demographics, comorbidities, and total number of medications using univariable and 
multivariable logistic regressions, where only covariates independently associated with PIM use $(\mathrm{p}<0.05)$ in univariable analyses were included in the multivariable model.

We calculated incidence rates for hospitalization and death per 100 person-years in the full cohort. We used univariable and multivariable zero-inflated negative binomial regression with robust variance estimators to calculate incidence rate ratios for hospitalization comparing categories of polypharmacy, and comparing those with and without PIM use, assessing for interactions between CKD status and both polypharmacy (categorical) and PIM use. We used a zero-inflated model to account for frequent zero-value observations and over-dispersed data. After assessing proportionality using a global test of Schoenfeld residuals, we performed similar analyses using Cox proportional hazards regression to evaluate associations with all-cause mortality. In addition, to evaluate for non-linear associations between the number of medications (continuous) and each of the outcomes, we modeled total number of medications as a cubic spline using four medications as the reference; we also assessed for interactions by CKD status. For hospitalization and death analyses, we assessed age-based PIM use in the full cohort, and kidney-based or combined kidney- and age-based PIM use among only those with CKD at visit five. In the latter analyses, we did not include the use of aspirin-containing products as a kidney-based PIM, since aspirin use was very common in the cohort.

We adjusted all analyses for age, sex, race, BMI, eGFR, LDL cholesterol, HDL cholesterol, triglycerides, smoking status, alcohol consumption, MMSE score, hypertension, diabetes, heart failure, cardiovascular disease, self-reported MI, CCI, frailty, and total vitamins/ supplements. In PIM-based analyses, we additionally adjusted for participants' total number of medications (continuous).

All analyses were done using Stata 14 (StataCorp, 2015; College, Station, TX).

\section{RESULTS}

The study population was $58.7 \%$ female, $23.0 \%$ African American, and had a mean age of 76.3 years $( \pm 5.2)$ (Table 1$)$. The majority had hypertension $(69.8 \%)$, and $32.4 \%, 18.6 \%$, $14.7 \%$ had diabetes mellitus, heart failure, and cardiovascular disease, respectively. The mean Charlson Comorbidity Index (CCI) was $4.2( \pm 1.8)$, and mean CCI was greater in higher CKD stages. The presence of CKD was common, with $29.1 \%(\mathrm{~N}=1,857)$ of the cohort having an eGFR $<60 \mathrm{~mL} / \mathrm{min} / 1.73 \mathrm{~m}^{2}$. Twenty-one percent had an albumin-tocreatinine ratio of $30 \mathrm{mg} / \mathrm{g}$ or higher.

Antihypertensive medications were the most commonly-used medication group ( $\mathrm{N}=4,819$, $75.4 \%)$, with beta-blockers the most common antihypertensive class ( $\mathrm{N}=2,141,33.5 \%)$ (Figure 1). Roughly 60\% (N=2,859) of those reporting antihypertensive use took two or more antihypertensive medications, and $25.4 \%(\mathrm{~N}=1,225)$ reported three or more (Electronic Supplementary Material Figure S2). Lipid-lowering agents were also commonly reported $(\mathrm{N}=3,556,55.6 \%)$, with over $10 \%(\mathrm{~N}=373)$ using two or more lipid-lowering agents in the prior 30 days. The use of diabetes medications was not as common among participants overall ( $\mathrm{N}=1,272,19.9 \%)$, but many of those reporting use of diabetes medicines reported 
using two or more such treatments $(\mathrm{N}=532,41.8 \%)$. As for analgesics, opioid medications were used in $10.5 \%(\mathrm{~N}=668)$ of participants, and of those, $8.4 \%(\mathrm{~N}=56)$ reporting using more than one opioid during the prior 30 days; the use of NSAID-containing (27.3\%) and aspirin-containing (59.4\%) products were much more common overall. The proportion of participants taking at least one medication within a medication class generally increased with decreasing eGFR, except for ACE inhibitors, bisphosphonates, antidepressants, anxiolytic/hypnotic/sedatives, and aspirin-containing and other NSAID-containing products (Figure 1). Among participants who did not attend visit five, self-reported medication use at their last 6-month phone interview was similar to those who did attend visit five (Electronic Supplementary Material Figure S3).

On average, participants reported using $6.1( \pm 3.5)$ medications and $2.3( \pm 2.2)$ vitamins or supplements. Overall, 24.3\% ( $\mathrm{N}=1,553), 23.7 \%(\mathrm{~N}=1,518), 36.0 \%(\mathrm{~N}=2,302)$, and $15.9 \%$ $(\mathrm{N}=1,019)$ of the cohort reported using $0-3,4-5,6-9$, and 10 or more prescription or OTC medications in the prior 30 days, respectively (Table 2). More than $35 \%$ of participants used 10 or more products when the use of medications, vitamins, and supplements were combined. Use of ten or more medications was more common among participants with CKD than without CKD $(22.7 \%$ versus $13.2 \%, \mathrm{p}<0.001)$. Although participants with CKD reported using more medications than those without CKD (mean 7.0 versus mean 5.7, $\mathrm{p}<0.001$ ), they used slightly fewer vitamins or supplements (mean 2.1 versus mean 2.3 , $\mathrm{p}<0.001)$.

The association between higher CKD stage and greater number of medications used persisted in adjusted analyses. For example, participants with stage G4 or G5 took an average of 1.32 (95\% confidence intervals (CI) 0.73-1.90) more medications than those with stage G1 or G2 (Table 2). After adjustment, other correlates of greater numbers of medications included heart failure, cardiovascular disease, diabetes mellitus, hypertension, self-reported previous MI, higher CCI, frailty, female sex, white race (compared to African American), higher BMI, higher total numbers of vitamins/supplements, higher triglycerides, lower LDL cholesterol, and lower MMSE (Electronic Supplementary Material Table S1).

Age-based PIM use based on Beers and STOPP criteria occurred in 31.3\% $(\mathrm{N}=2,001)$ of the full cohort (Electronic Supplementary Material Electronic Supplementary Material Table $\mathrm{S} 2$ ), and $32.7 \%$ ( $\mathrm{N}=608$ ) of the participants with CKD. The most common age-based PIMs were first-generation antihistamines, benzodiazepines, oral estrogens, and zolpidem. In univariable and multivariable analyses, age-based PIM use was associated with higher total number of medications, CCI, female sex, and no diabetes mellitus or hypertension (data not shown).

Out of the 554 reported medications, 52 unique medications and 19 NSAID-containing products were identified as potentially inappropriate based on kidney function in at least one of the references. Kidney-based PIM use was common among those in CKD stage G4 or G5 $(\mathrm{N}=36,35.6 \%)$, and somewhat less common in those with CKD stage G3a or G3b ( $\mathrm{N}=223$, $12.7 \%)$ (Table 3). The most common kidney-based PIMs were metformin ( $\mathrm{N}=42)$ and NSAID-containing products ( $\mathrm{N}=632$ ). Some other commonly used kidney-based PIMs included fenofibrate, spironolactone, gabapentin, alendronate, and hydrochlorothiazide- 
containing products. Among people with CKD, kidney-based PIM use was associated with lower eGFR, higher total number of medications, female sex, and no self-reported MI in univariable and multivariable analyses (data not shown).

Among the 6,379 participants with post-visit 5 follow-up, median follow-up was 2.6 years (interquartile range: 0.8 years). There were 4,178 hospitalizations in 2,197 cohort members (34.4\%) over 16,111 person-years of follow-up. Overall, the incidence rate for hospitalization was 26 per 100 person-years (Table 4). Hospitalization incidence increased with greater number of medications $(15,18,29$, and 49 per 100 person-years for $0-3,4-5$, $6-9$, and 10 or more medications, respectively). For each category of polypharmacy, participants with CKD had higher absolute risks of hospitalization than those without CKD; however, there were no differences in the relative risks by CKD status (all $\mathrm{p}$ for interaction $>0.1$ ). In the continuous analysis, there was a non-linear relationship between total number of medications and the risk of hospitalization (Figure 2), with no statistically significant difference by CKD status. Compared to four medications, the use of five medications was associated with a $15 \%$ higher risk of hospitalization (95\% CI: 7\%-24\%), with increasing numbers of medications associated with increasing risk after five medications. With respect to PIM use, although those with age- or kidney-based PIM use had higher hospitalization rates than those without, these risks did not persist in adjusted analyses.

There were 344 deaths during the follow-up period, with an incidence rate of 2 deaths per 100 person-years (Table 4). Similar to hospitalization, incidence of death increased with greater number of medications $(1,1,3$, and 4 per 100 person-years for $0-3,4-5,6-9$, and 10 or more medications, respectively). For each category of polypharmacy, participants with CKD had higher absolute risks of death than those without CKD; however, like hospitalization, there were no differences in the relative risks by CKD status (all $\mathrm{p}$ for interaction >0.1). In continuous analysis, there was a non-linear relationship between total number of medications and the risk of death (Figure 3), with a suggestion of higher risk with less than four medications. There was no statistically significant difference in the association of total number of medications and mortality by CKD status. Compared to four medications, the use of five and six medications were not associated with increases in risk, but seven medications was associated with a $60 \%$ increase in the risk of death (95\% CI: $12 \%-128 \%)$, with increasing numbers of medications associated with increasing hazard ratios until plateauing after 11 medications. Age- or kidney-based PIM use was not associated with death.

\section{DISCUSSION}

In this community-based cohort of older adults, approximately one in six participants used 10 or more medications, and more than one in three used 10 or more products when the use of medications, vitamins, and supplements were combined. Higher numbers of medications were more common among those with lower eGFR, and were associated with greater risks of hospitalization and death. Age-based PIM and kidney-based PIM use were also common in the cohort, but were associated with hospitalization only in unadjusted analyses, and not associated with mortality risk. Our findings underscore the value of routine assessments of 
medication use among older adults, and suggest that minimizing unnecessary medication use may be an approach to reducing morbidity and mortality.

Some have hypothesized that polypharmacy may be a surrogate marker of inappropriate medication use as it can increase the risk of adverse drug effects (ADEs), $(5,9)$ and adverse drug-drug and drug-disease interactions. (14) A study by Onder et al (18) found that the primary risk factor for ADE-related hospitalization in older adults was polypharmacy. Other studies have assessed the risk of mortality in older adults with polypharmacy, and how various comorbidities differentially affect that risk. $(15,16,21)$ A recent study by Schöttker et al (15) observed that those taking 10 or more medications with fewer concurrent comorbidities had a higher relative risk of non-cancer mortality than those with more concurrent comorbidities. We hypothesized that the interaction between polypharmacy and comorbidities might be driven in part by the presence of CKD, where ADEs are particularly common $(40,61,62)$; however, we found similar risk relationships associated in persons with and without CKD.

An interesting finding from this study was the non-linear relationship between total number of medications and mortality. Our results suggested a potentially higher mortality risk among participants with fewer medications. Although not significant, the U-shaped association between total number of medications and mortality could represent medication underuse, but perhaps it is more likely a result of residual confounding with providers reducing the number of medications in patients with poorer health status. Participants using higher numbers of medications generally had a higher mortality risk, which may reflect a more severe disease phenotype.

Surprisingly, both kidney- and age-based PIM use were not associated with adverse outcomes in our study. While prior studies have been somewhat equivocal with respect to these associations, our results differ from those which showed an increased risk in morbidity and mortality associated with PIM use. $(24,44-47)$ Our null results suggest that the risks associated with PIM use in older adults may be minimal due to an increase in provider monitoring, or may be specific to certain medications used in specific clinical situations not captured in a community-based cohort. For example, most kidney-based PIM use was due to metformin and NSAIDs, and metformin use at lower eGFRs is now increasingly recognized as acceptable clinical practice. There is also the potential for channeling bias, whereby only healthy or adherent people were prescribed medications deemed contraindicated, and in whom the benefits were considered to outweigh any apparent risks. It is also possible that using a "prevalent user" design selected out participants susceptible to the effects of PIM use, leaving only patients where these medications could be tolerated. (24) The observed reductions in the reported number of vitamins and supplements with decreasing levels of kidney function in this study suggest that patients may heed some provider warnings about PIM use; however, the high proportion of NSAID use seen in those with CKD runs counter to that suggestion. Regardless, coordinated prescribing and an increase in clinical assessments of common physiological changes as a result of aging, including reduced kidney function, could further prevent inappropriate or unnecessary medication use. $(11,63)$ 
One major impediment to preventing age- or kidney-based PIM use is the inconsistency between medication guidelines for older adult patients (39) and those with reduced kidney function. $(38,40,41)$ There is no gold standard reference with which to determine contraindication in either group, which can lead to confusion on appropriate prescribing. This can also lead to inconsistent findings between studies with different operationalized definitions of PIM use, and may be a reason why this and some other investigations have observed a null result with respect to PIM use. $(21,43,48-51)$ In this analysis, we found that the accessed medication references often varied in which drugs were contraindicated or recommended to avoid based on kidney function, used several different kidney function metrics, and in several instances, provided only qualitative guidelines without a specific level of kidney function noted. This lack of granularity may be a result of expansive exclusion criteria, such as older patients and those with CKD, in pre-market pharmacokinetic and safety studies. (64) In the absence of such data, recommendations may be quite subjective; moreover, medication resources often inconsistently report what data were used to formulate a recommendation. $(39,41)$

Our study had several strengths. The ARIC cohort is a well-established cohort of older adults from several geographically diverse communities. Because cohort members have a comprehensive physical exam at study visits, rich clinical data exist on each participant, including labs. Actual medication use was captured, rather than dispensed medications, and OTC medications, vitamins and supplements are also recorded.

Our study also had several limitations. Analyses were limited to participants who attended visit five and may not include participants unable to attend based on their health status; however, for those who did not attend, last reported medication use from phone interviews was similar to those included in the study cohort. Because medication use was captured as any use in the prior 30 days at a single visit, contraindicated drug-drug interactions and concurrent duplicate medication use could not be assessed. We could not assess PIM use with respect to dosing as dose information was unavailable. Medication use was captured through a patient inventory at their study visit and was therefore dependent on the participant bringing in the medications, or self-reporting use in the prior 30 days. Few patients had eGFR $<45 \mathrm{ml} / \mathrm{min} / 1.73 \mathrm{~m}^{2}$, and we had no information on specialist care. If medication management was undertaken by a kidney specialist in those with more advanced CKD, medication-related adverse events may be mitigated, possibly contributing to the lack of effect modification by CKD status. As with any pharmacoepidemiologic investigation, despite controlling for numerous confounders, residual confounding by indication is possible. Finally, this study used a "prevalent user" design rather than assess risk after exposure initiation, therefore the population may lack persons who experienced adverse events early during polypharmacy or PIM use.

\section{CONCLUSIONS}

We found that polypharmacy and PIM use were relatively common in older adults, and that higher numbers of medications were associated with higher risk of hospitalization and mortality. Unexpectedly, while age- and kidney-based PIM use were common, they were not associated with hospitalization or mortality after adjustment for other covariates. Although 
CKD was associated with higher absolute risk of hospitalization and death across all categories of medication use, the relative risk associated with greater number of medications was not different by CKD status. Greater coordination of care across providers may help to reduce the prevalence of polypharmacy and PIM use in populations who are particularly vulnerable to adverse events from medications.

\section{Supplementary Material}

Refer to Web version on PubMed Central for supplementary material.

\section{Acknowledgments}

The authors thank the staff and participants of the ARIC study for their important contributions.

Support: The principle author, AS, is supported by grant T32 HL007024 from the National Heart, Lung, and Blood Institute (NHLBI), National Institutes of Health (NIH). MG is supported by grant K08DK092287 from the National Institute of Diabetes and Digestive and Kidney Diseases. GCA is supported by 1 U01 FD004977-02 from the U.S. Food and Drug Administration (FDA). The Atherosclerosis Risk in Communities study is performed as a collaborative investigation supported by contracts HHSN268201100005C, HHSN268201100006C, HHSN268201100007C, HHSN268201100008C, HHSN268201100009C, HHSN268201100010C, HHSN268201100011C, and HHSN268201100012C from the National Heart, Lung, and Blood Institute. The funding sources had no role in the design and conduct of the study, analysis or interpretation of the data, and preparation or final approval of the manuscript prior to publication.

Funding:

The principal author Alex Secora is supported by grant T32 HL007024 from the National, Heart, Lung, and Blood Institute (NHLBI), National Institutes of Health (NIH). Morgan Grams is supported by grant K08DK092287 from the National Institute of Diabetes and Digestive and Kidney Diseases. G. Caleb Alexander is supported by 1 U01 FD004977-02 from the U.S. Food and Drug Administration (FDA). The Atherosclerosis Risk in Communities (ARIC) study is performed as a collaborative investigation supported by contracts HHSN268201100005C, HHSN268201100006C, HHSN268201100007C, HHSN268201100008C, HHSN268201100009C, HHSN268201100010C, HHSN268201100011C, and HHSN268201100012C from the NHLBI. The funding sources had no role in the design and conduct of the study, analysis or interpretation of, the data, and preparation or final approval of the manuscript prior to publication.

\section{References}

1. He W, Goodkind D, Kowal P. An aging world: 2015 international population reports. Washington, D.C: U.S. Government Publishing Office; Mar, 2016

2. Coresh J, Selvin E, Stevens LA, Manzi J, Kusek JW, Eggers P, et al. Prevalence of chronic kidney disease in the United States. JAMA. 2007; 298(17):2038-47. [PubMed: 17986697]

3. Lassiter J, Bennett WM, Olyaei AJ. Drug dosing in elderly patients with chronic kidney disease. Clin Geriatr Med. 2013; 29(3):657-705. [PubMed: 23849014]

4. Masoudi FA, Baillie CA, Wang Y, Bradford WD, Steiner JF, Havranek EP, et al. The complexity and cost of drug regimens of older patients hospitalized with heart failure in the United States, 1998-2001. Arch Intern Med. 2005; 165(18):2069-76. [PubMed: 16216996]

5. Bushardt RL, Massey EB, Simpson TW, Ariail JC, Simpson KN. Polypharmacy: misleading, but manageable. Clin Interv Aging. 2008; 3(2):383-9. [PubMed: 18686760]

6. Slabaugh SL, Maio V, Templin M, Abouzaid S. Prevalence and risk of polypharmacy among the elderly in an outpatient setting: a retrospective cohort study in the Emilia-Romagna region, Italy. Drugs Aging. 2010; 27(12):1019-28. [PubMed: 21087071]

7. Banerjee A, Mbamalu D, Ebrahimi S, Khan AA, Chan TF. The prevalence of polypharmacy in elderly attenders to an emergency department - a problem with a need for an effective solution. Int $\mathbf{J}$ Emerg Med. 2011; 4(1):22. [PubMed: 21635734] 
8. Rohrer JE, Garrison G, Oberhelman SA, Meunier MR. Epidemiology of polypharmacy among family medicine patients at hospital discharge. J Prim Care Community Health. 2013; 4(2):101-5. [PubMed: 23799716]

9. Qato DM, Alexander GC, Conti RM, Johnson M, Schumm P, Lindau ST. Use of prescription and over-the-counter medications and dietary supplements among older adults in the United States. JAMA. 2008; 300(24):2867-78. [PubMed: 19109115]

10. Sharma M, Loh KP, Nightingale G, Mohile SG, Holmes HM. Polypharmacy and potentially inappropriate medication use in geriatric oncology. J Geriatr Oncol. 2016; 7(5):346-53. [PubMed: 27498305]

11. Wooten JM. Pharmacotherapy considerations in elderly adults. South Med J. 2012; 105(8):437-45. [PubMed: 22864103]

12. Papaioannou A, Clarke JA, Campbell G, Bedard M. Assessment of adherence to renal dosing guidelines in long-term care facilities. J Am Geriatr Soc. 2000; 48(11):1470-3. [PubMed: 11083325]

13. Chang F, O'Hare AM, Miao Y, Steinman MA. Use of Renally Inappropriate Medications in Older Veterans: A National Study. J Am Geriatr Soc. 2015; 63(11):2290-7. [PubMed: 26503124]

14. Goldberg RM, Mabee J, Chan L, Wong S. Drug-drug and drug-disease interactions in the ED: analysis of a high-risk population. Am J Emerg Med. 1996; 14(5):447-50. [PubMed: 8765105]

15. Schottker B, Saum KU, Muhlack DC, Hoppe LK, Holleczek B, Brenner H. Polypharmacy and mortality: new insights from a large cohort of older adults by detection of effect modification by multi-morbidity and comprehensive correction of confounding by indication. Eur J Clin Pharmacol. 2017; 73(8):1041-8. [PubMed: 28540438]

16. Herr M, Robine JM, Pinot J, Arvieu JJ, Ankri J. Polypharmacy and frailty: prevalence, relationship, and impact on mortality in a French sample of 2350 old people. Pharmacoepidemiol Drug Saf. 2015; 24(6):637-46. [PubMed: 25858336]

17. Flaherty JH, Perry HM, Lynchard GS, Morley JE. Polypharmacy and hospitalization among older home care patients. J Gerontol A Biol Sci Med Sci. 2000; 55(10):554.

18. Onder G, Pedone C, Landi F, Cesari M, Della Vedova C, Bernabei R, et al. Adverse drug reactions as cause of hospital admissions: results from the Italian Group of Pharmacoepidemiology in the Elderly (GIFA). J Am Geriatr Soc. 2002; 50(12):1962-8. [PubMed: 12473007]

19. Hellden A, Bergman U, von Euler M, Hentschke M, Odar-Cederlof I, Ohlen G. Adverse drug reactions and impaired renal function in elderly patients admitted to the emergency department: a retrospective study. Drugs Aging. 2009; 26(7):595-606. [PubMed: 19655826]

20. Leendertse AJ, van Dijk EA, De Smet PA, Egberts TC, van den Bemt PM. Contribution of renal impairment to potentially preventable medication-related hospital admissions. Ann Pharmacother. 2012; 46(5):625-33. [PubMed: 22570433]

21. Espino DV, Bazaldua OV, Palmer RF, Mouton CP, Parchman ML, Miles TP, et al. Suboptimal medication use and mortality in an older adult community-based cohort: results from the Hispanic EPESE Study. J Gerontol A Biol Sci Med Sci. 2006; 61(2):170-5. [PubMed: 16510861]

22. Gurwitz JH, Field TS, Harrold LR, Rothschild J, Debellis K, Seger AC, et al. Incidence and preventability of adverse drug events among older persons in the ambulatory setting. JAMA. 2003; 289(9):1107-16. [PubMed: 12622580]

23. Rich MW. Pharmacotherapy of heart failure in the elderly: adverse events. Heart Fail Rev. 2012; 17(4-5):589-95. [PubMed: 21688185]

24. Muhlack DC, Hoppe LK, Weberpals J, Brenner H, Schottker B. The association of potentially inappropriate medication at older age with cardiovascular events and overall mortality: a systematic review and meta-analysis of cohort studies. J Am Med Dir Assoc. 2017; 18(3):211-20. [PubMed: 28131719]

25. Doogue MP, Polasek TM. Drug dosing in renal disease. Clin Biochem Rev. 2011; 32(2):69-73. [PubMed: 21611079]

26. Hassan Y, Al-Ramahi R, Abd Aziz N, Ghazali R. Drug use and dosing in chronic kidney disease. Ann Acad Med Singapore. 2009; 38(12):1095-103. [PubMed: 20052447]

27. Verbeeck RK, Musuamba FT. Pharmacokinetics and dosage adjustment in patients with renal dysfunction. Eur J Clin Pharmacol. 2009; 65(8):757-73. [PubMed: 19543887] 
28. Hartmann B, Czock D, Keller F. Drug therapy in patients with chronic renal failure. Dtsch Arztebl Int. 2010; 107(37):6.

29. Via-Sosa MA, Lopes N, March M. Effectiveness of a drug dosing service provided by community pharmacists in polymedicated elderly patients with renal impairment-a comparative study. BMC Fam Pract. 2013; 14:96. [PubMed: 23849005]

30. Hanlon JT, Wang X, Handler SM, Weisbord S, Pugh MJ, Semla T, et al. Potentially inappropriate prescribing of primarily renally cleared medications for older veterans affairs nursing home patients. J Am Med Dir Assoc. 2011; 12(5):377-83. [PubMed: 21450179]

31. Nielsen AL, Henriksen DP, Marinakis C, Hellebek A, Birn H, Nybo M, et al. Drug dosing in patients with renal insufficiency in a hospital setting using electronic prescribing and automated reporting of estimated glomerular filtration rate. Basic Clin Pharmacol Toxicol. 2014; 114(5):40713. [PubMed: 24373255]

32. Falconnier AD, Haefeli WE, Schoenenberger RA, Surber C, Martin-Facklam M. Drug dosage in patients with renal failure optimized by immediate concurrent feedback. J Gen Intern Med. 2001; 16(6):369-75. [PubMed: 11422633]

33. Chertow GM, Lee J, Kuperman GJ, Burdick E, Horsky J, Seger DL, et al. Guided medication dosing for inpatients with renal insufficiency. JAMA. 2001; 286(22):2839-44. [PubMed: 11735759]

34. van Dijk EA, Drabbe NR, Kruijtbosch M, De Smet PA. Drug dosage adjustments according to renal function at hospital discharge. Ann Pharmacother. 2006; 40(7-8):1254-60. [PubMed: 16804098]

35. Blix HS, Viktil KK, Moger TA, Reikvam A. Use of renal risk drugs in hospitalized patients with impaired renal function-an underestimated problem? Nephrol Dial Transplant. 2006; 21(11): 3164-71. [PubMed: 16880181]

36. Parker K, Aasebo W, Stavem K. Potentially inappropriate medications in elderly haemodialysis patients using the STOPP criteria. Drugs Real World Outcomes. 2016; 3(3):359-63. [PubMed: 27747833]

37. Sheen SS, Choi JE, Park RW, Kim EY, Lee YH, Kang UG. Overdose rate of drugs requiring renal dose adjustment: data analysis of 4 years prescriptions at a tertiary teaching hospital. J Gen Intern Med. 2008; 23(4):423-8. [PubMed: 18373140]

38. Khanal A, Castelino RL, Peterson GM, Jose MD. Dose adjustment guidelines for medications in patients with renal impairment: how consistent are drug information sources? Intern Med J. 2014; 44(1):77-85. [PubMed: 24112311]

39. Hanlon JT, Aspinall SL, Semla TP, Weisbord SD, Fried LF, Good CB, et al. Consensus guidelines for oral dosing of primarily renally cleared medications in older adults. J Am Geriatr Soc. 2009; 57(2):335-40. [PubMed: 19170784]

40. Richardson MM, Nolin TD. A decade after the KDOQI CKD guidelines: impact on medication safety. Am J Kidney Dis. 2012; 60(5):713-5. [PubMed: 23067638]

41. Vidal L, Shavit M, Fraser A, Paul M, Leibovici L. Systematic comparison of four sources of drug information regarding adjustment of dose for renal function. BMJ. 2005; 331(7511):263. [PubMed: 15905228]

42. KDIGO Clinical Practice Guideline for the Management of Blood Pressure in Chronic Kidney Disease. Kidney International Supplements, International Society of Nephrology; Dec, 2012

43. Klarin I, Wimo A, Fastbom J. The association of inappropriate drug use with hospitalisation and mortality: a population-based study of the very old. Drugs Aging. 2005; 22(1):69-82. [PubMed: 15663350]

44. Lau DT, Kasper JD, Potter DE, Lyles A, Bennett RG. Hospitalization and death associated with potentially inappropriate medication prescriptions among elderly nursing home residents. Arch Intern Med. 2005; 165(1):68-74. [PubMed: 15642877]

45. Dedhiya SD, Hancock E, Craig BA, Doebbeling CC, Thomas J. Incident use and outcomes associated with potentially inappropriate medication use in older adults. Am J Geriatr Pharmacother. 2010; 8(6):562-70. [PubMed: 21356505] 
46. Lu WH, Wen YW, Chen LK, Hsiao FY. Effect of polypharmacy, potentially inappropriate medications and anticholinergic burden on clinical outcomes: a retrospective cohort study. CMAJ. 2015; 187(4):130. [PubMed: 25534597]

47. Skoldunger A, Fastbom J, Wimo A, Fratiglioni L, Johnell K. Impact of inappropriate drug use on hospitalizations, mortality, and costs in older persons and persons with dementia: findings from the SNAC study. Drugs Aging. 2015; 32(8):671-8. [PubMed: 26232101]

48. Pozzi C, Lapi F, Mazzaglia G, Inzitari M, Boncinelli M, Geppetti P, et al. Is suboptimal prescribing a risk factor for poor health outcomes in community-dwelling elders? The ICARe Dicomano study. Pharmacoepidemiol Drug Saf. 2010; 19(9):954-60. [PubMed: 20623521]

49. Barnett K, McCowan C, Evans JM, Gillespie ND, Davey PG, Fahey T. Prevalence and outcomes of use of potentially inappropriate medicines in older people: cohort study stratified by residence in nursing home or in the community. BMJ Qual Saf. 2011; 20(3):275-81.

50. Beer C, Hyde Z, Almeida OP, Norman P, Hankey GJ, Yeap BB, et al. Quality use of medicines and health outcomes among a cohort of community dwelling older men: an observational study. $\mathrm{Br} \mathbf{J}$ Clin Pharmacol. 2011; 71(4):592-9. [PubMed: 21395652]

51. Lin HY, Liao CC, Cheng SH, Wang PC, Hsueh YS. Association of potentially inappropriate medication use with adverse outcomes in ambulatory elderly patients with chronic diseases: experience in a Taiwanese medical setting. Drugs Aging. 2008; 25(1):49-59. [PubMed: 18184029]

52. The Atherosclerosis Risk in Communities (ARIC) Study: design and objectives. The ARIC investigators. Am J Epidemiol. 1989; 129(4):687-702. [PubMed: 2646917]

53. KDIGO Clinical Practice Guideline for the Evaluation and Management of Chronic Kidney Disease. Kidney International Supplements, International Society of Nephrology; 2013.

54. Ballew SH, Chen Y, Daya NR, Godino JG, Windham BG, McAdams-DeMarco M, et al. Frailty, Kidney Function, and Polypharmacy: The Atherosclerosis Risk in Communities (ARIC) Study. Am J Kidney Dis. 2017 Feb 01; 69(2):228-36. [PubMed: 27884475]

55. Quan H, Sundararajan V, Halfon P, Fong A, Burnand B, Luthi JC, et al. Coding algorithms for defining comorbidities in ICD-9-CM and ICD-10 administrative data. Med Care. 2005; 43(11): 1130-9. [PubMed: 16224307]

56. Deyo RA, Cherkin DC, Ciol MA. Adapting a clinical comorbidity index for use with ICD-9-CM administrative databases. J Clin Epidemiol. 1992; 45(6):613-9. [PubMed: 1607900]

57. Fick DM, Semla TP, Beizer J, Brandt N, Dombrowski R, DuBeau CE, et al. American Geriatrics Society 2015 updated Beers criteria for potentially inappropriate medication use in older adults. J Am Geriatr Soc. 2015; 63(11):2227-46. [PubMed: 26446832]

58. O’Mahony D, O’Sullivan D, Byrne S, O'Connor MN, Ryan C, Gallagher P. STOPP/START criteria for potentially inappropriate prescribing in older people: version 2. Age ageing. 2015; 44(2):213-8. [PubMed: 25324330]

59. Stevens LA, Nolin TD, Richardson MM, Feldman HI, Lewis JB, Rodby R, et al. Comparison of drug dosing recommendations based on measured GFR and kidney function estimating equations. Am J Kidney Dis. 2009; 54(1):33-42. [PubMed: 19446939]

60. Okparavero AA, Tighiouart H, Krishnasami Z, Wyatt CM, Graham H, Hellinger J, et al. Use of glomerular filtration rate estimating equations for drug dosing in HIV-positive patients. Antivir Ther. 2013; 18(6):793-802. [PubMed: 23963249]

61. Sharif-Askari FS, Syed Sulaiman SA, Saheb Sharif-Askari N, Al Sayed Hussain A. Development of an adverse drug reaction risk assessment score among hospitalized patients with chronic kidney disease. PLoS One. 2014; 9(4):e95991. [PubMed: 24755778]

62. Hug BL, Witkowski DJ, Sox CM, Keohane CA, Seger DL, Yoon C, et al. Occurrence of adverse, often preventable, events in community hospitals involving nephrotoxic drugs or those excreted by the kidney. Kidney Int. 2009; 76(11):1192-8. [PubMed: 19759525]

63. Page RL, O'Bryant CL, Cheng D, Dow TJ, Ky B, Stein CM, et al. Drugs that may cause or exacerbate heart failure: a scientific statement from the American Heart Association. Circulation. 2016; 134(6):32.

64. Zhang L, Xu N, Xiao S, Arya V, Zhao P, Lesko LJ, et al. Regulatory perspectives on designing pharmacokinetic studies and optimizing labeling recommendations for patients with chronic kidney disease. J clin pharm. 52(1 Suppl):90S. 


\section{Key points}

- It is common for older adults to use several medications at the same time and to use medications that are deemed inappropriate based on one's age or kidney function.

- While medication use deemed inappropriate based on one's age or kidney function was not associated with a greater risk of hospitalization or death in older adults, using greater numbers of medications was associated with a greater risk of hospitalization and death.

- Greater coordination of care across providers may help to reduce the prevalence of polypharmacy and PIM use in populations vulnerable to adverse events from medications. 


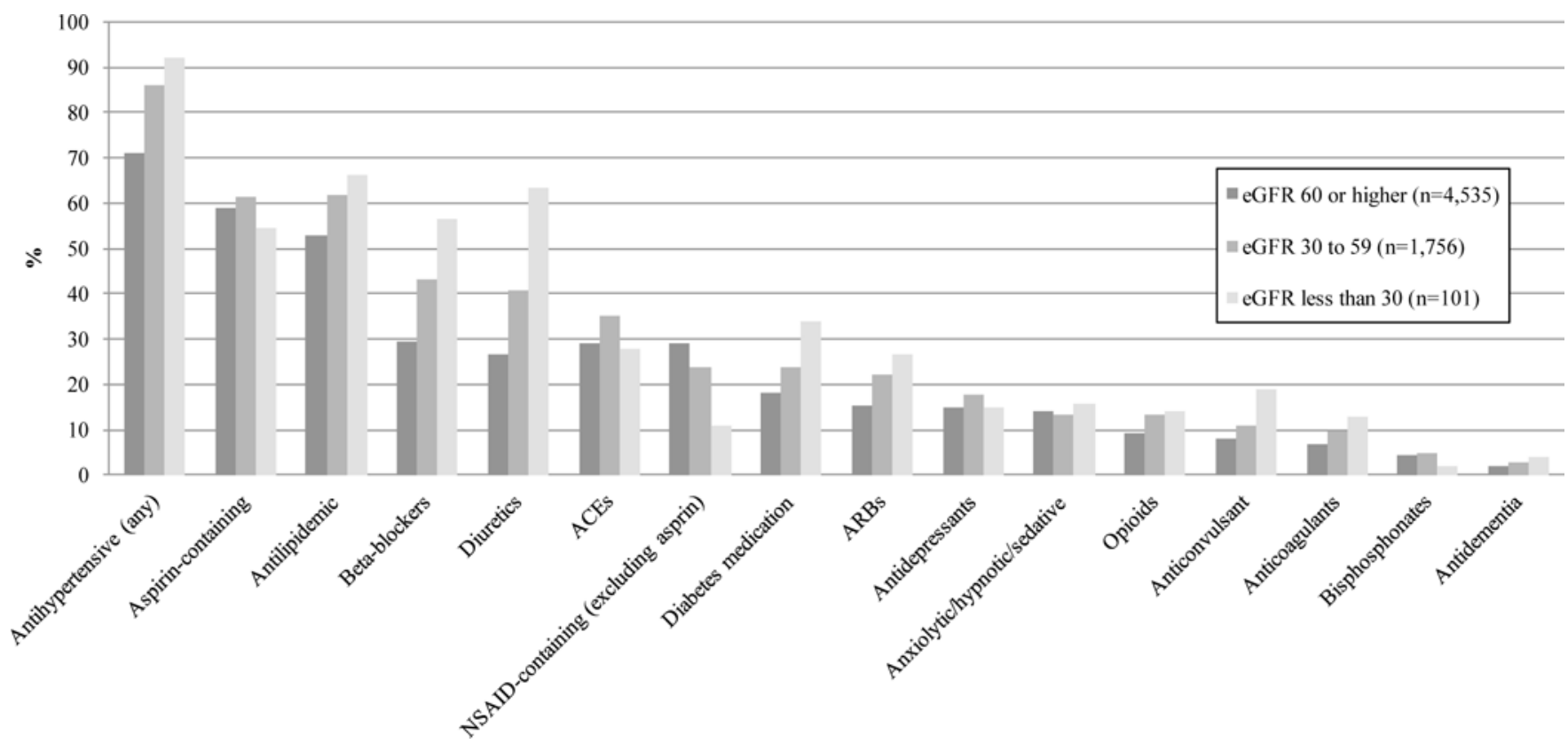

Figure 1. Proportion of participants reporting at least one medication in the prior 30 days, by category of medications

Categorized by estimated glomerular filtration rate (eGFR); units in $\mathrm{mL} / \mathrm{min} / 1.73 \mathrm{~m}^{2}$

Key: Nonsteroidal anti-inflammatory drug (NSAID); Angiotensin-converting-enzyme (ACE) inhibitor or ACE combination product; Angiotensin II receptor blockers (ARB) or ARB combination product; Antihypertensive includes diuretics, beta-blockers, calcium channel blockers, ACE/combination, and ARB/combination 


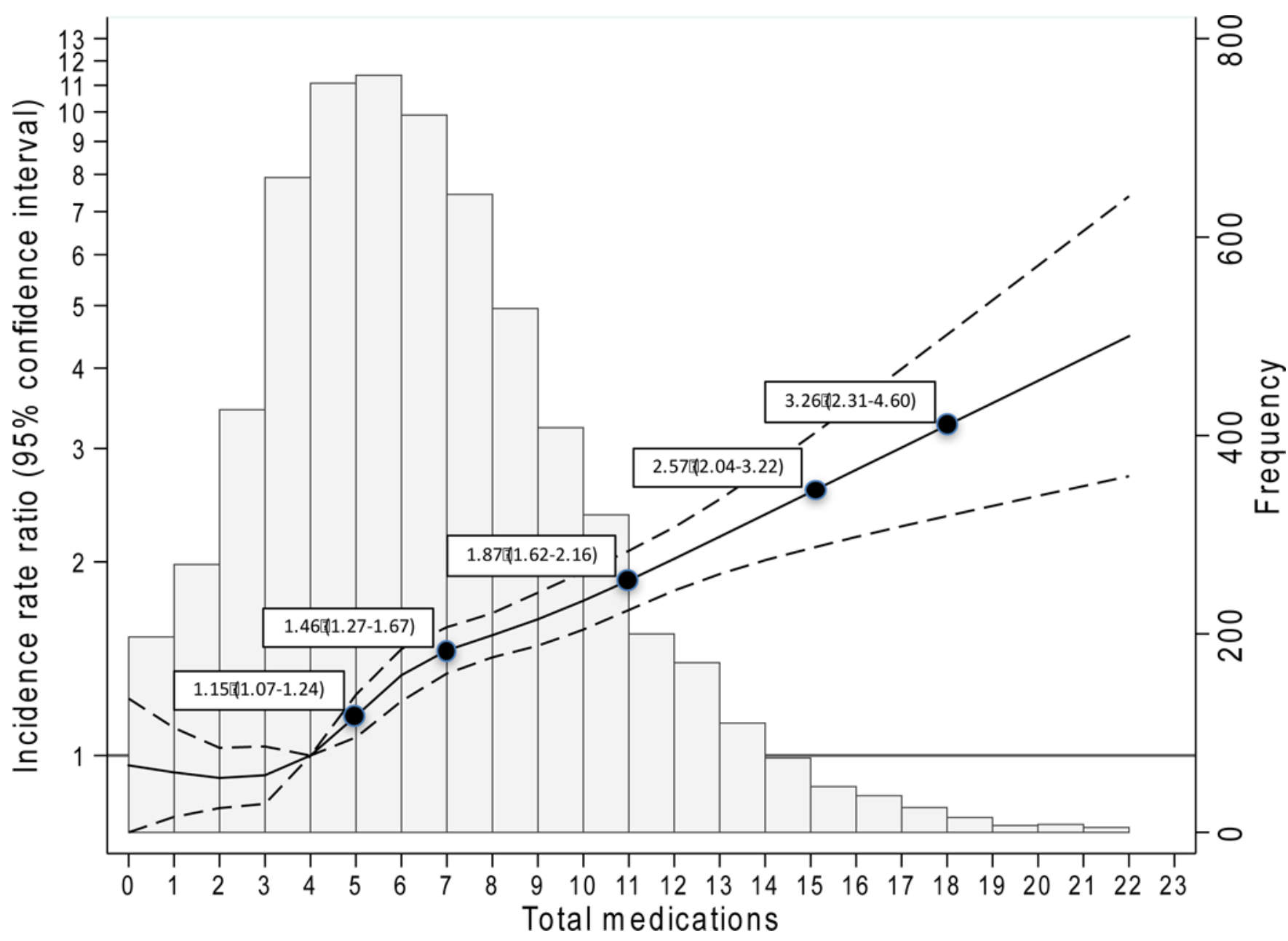

Figure 2. Risk of hospitalization across total number of medications

Key: Histogram depicts the distribution of total number of medications in the cohort (right y-axis). The solid black line (black dashed lines are 95\% confidence interval) is the adjusted incidence rate ratio, representing the average (covariates were centered at cohort means) participant's risk of hospitalization across total number of medications, relative to the reference (4 medications). Model was adjusted for estimated glomerular filtration rate, hypertension, cardiovascular disease, diabetes, heart failure, self-reported myocardial infarction, Charlson Comorbidity Index, frailty, sex, race, Age, Body Mass Index, current smoking status, current alcohol use, Mini-Mental State Evaluation, high-density lipoproteins, low-density lipoproteins, triglycerides, and total vitamins/supplements. 


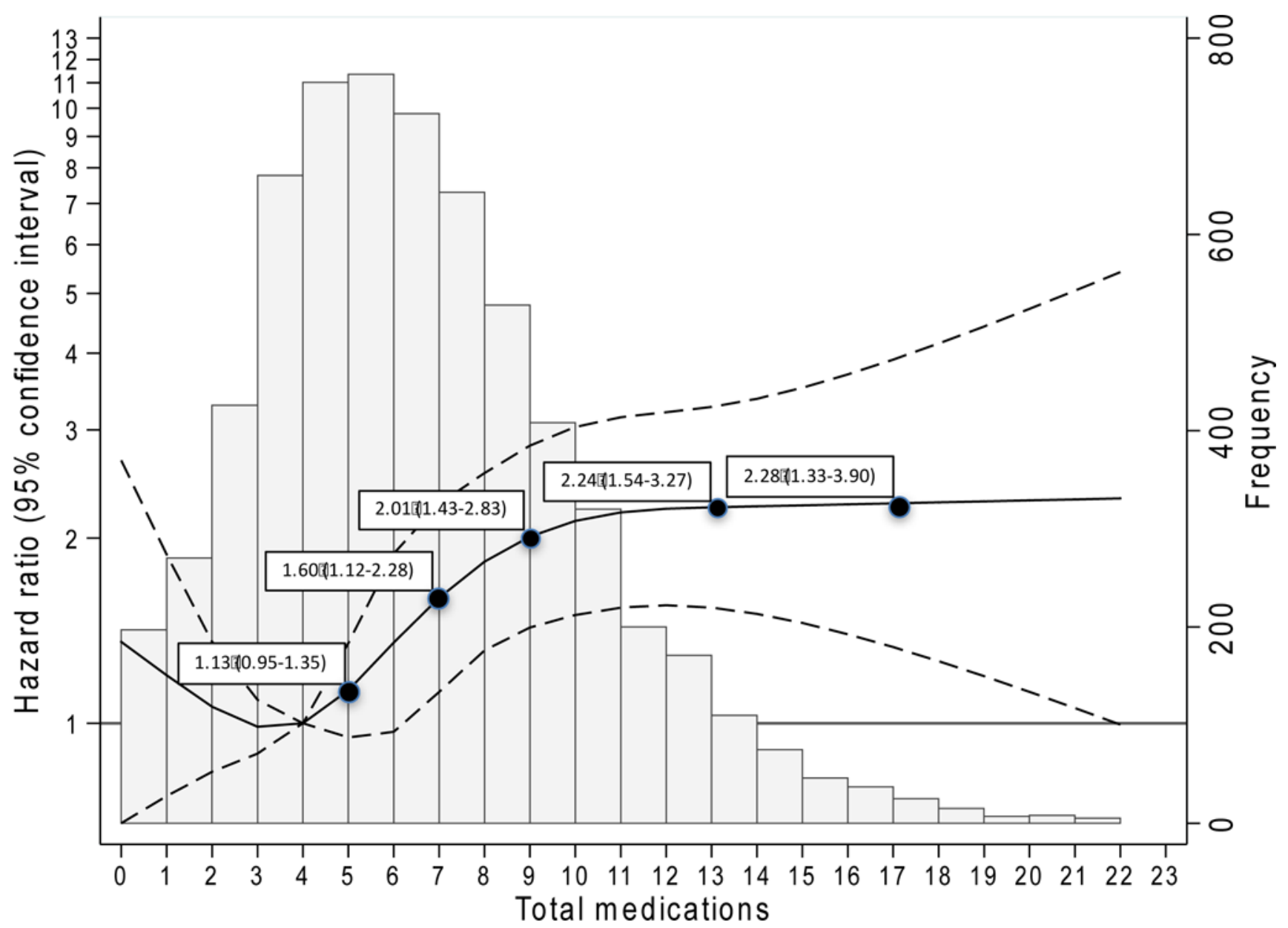

Figure 3. Risk of death across total number of medications

Key: Histogram depicts the distribution of total number of medications in the cohort (right y-axis). The solid black line (black dashed lines are 95\% confidence interval) is the adjusted hazard ratio, representing the average (covariates were centered at cohort means) participant's risk of death across total number of medications, relative to the reference (4 medications). Model was adjusted for estimated glomerular filtration rate, hypertension, cardiovascular disease, diabetes, heart failure, self-reported myocardial infarction, Charlson Comorbidity Index, frailty, sex, race, age, Body Mass Index, current smoking status, current alcohol use, Mini-Mental State Evaluation, high-density lipoproteins, low-density lipoproteins, triglycerides, and total vitamins/supplements. 


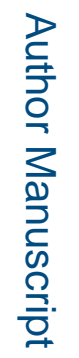

D
음
$\frac{1}{2}$
$\frac{0}{2}$
$\frac{2}{0}$
$\frac{0}{\bar{D}}$
우

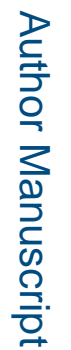

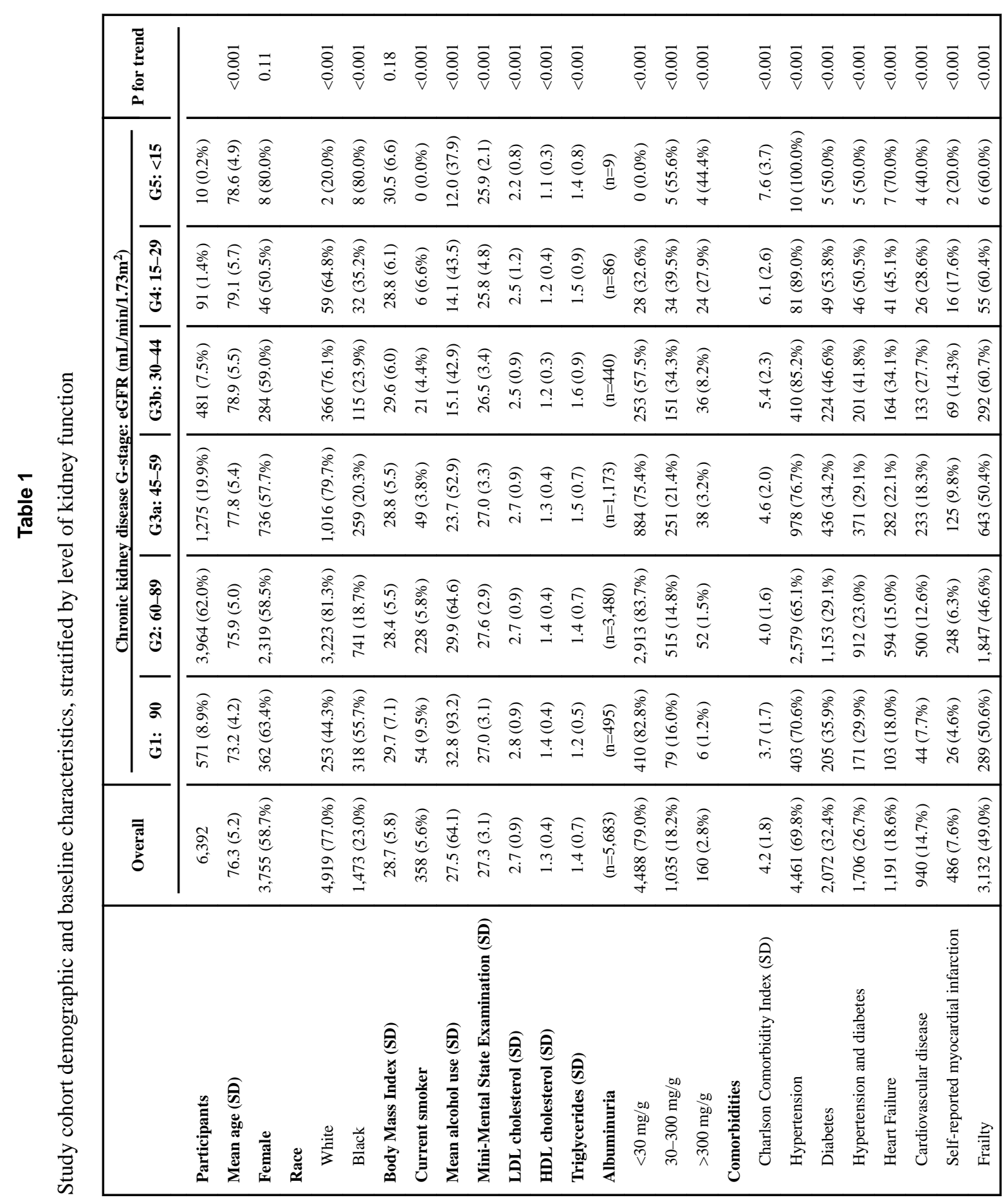

Drugs Aging. Author manuscript; available in PMC 2019 August 01. 


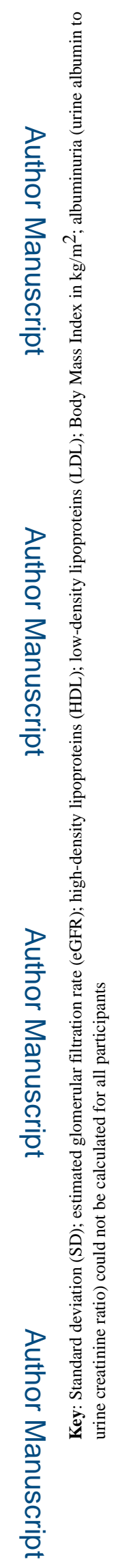

Drugs Aging. Author manuscript; available in PMC 2019 August 01. 


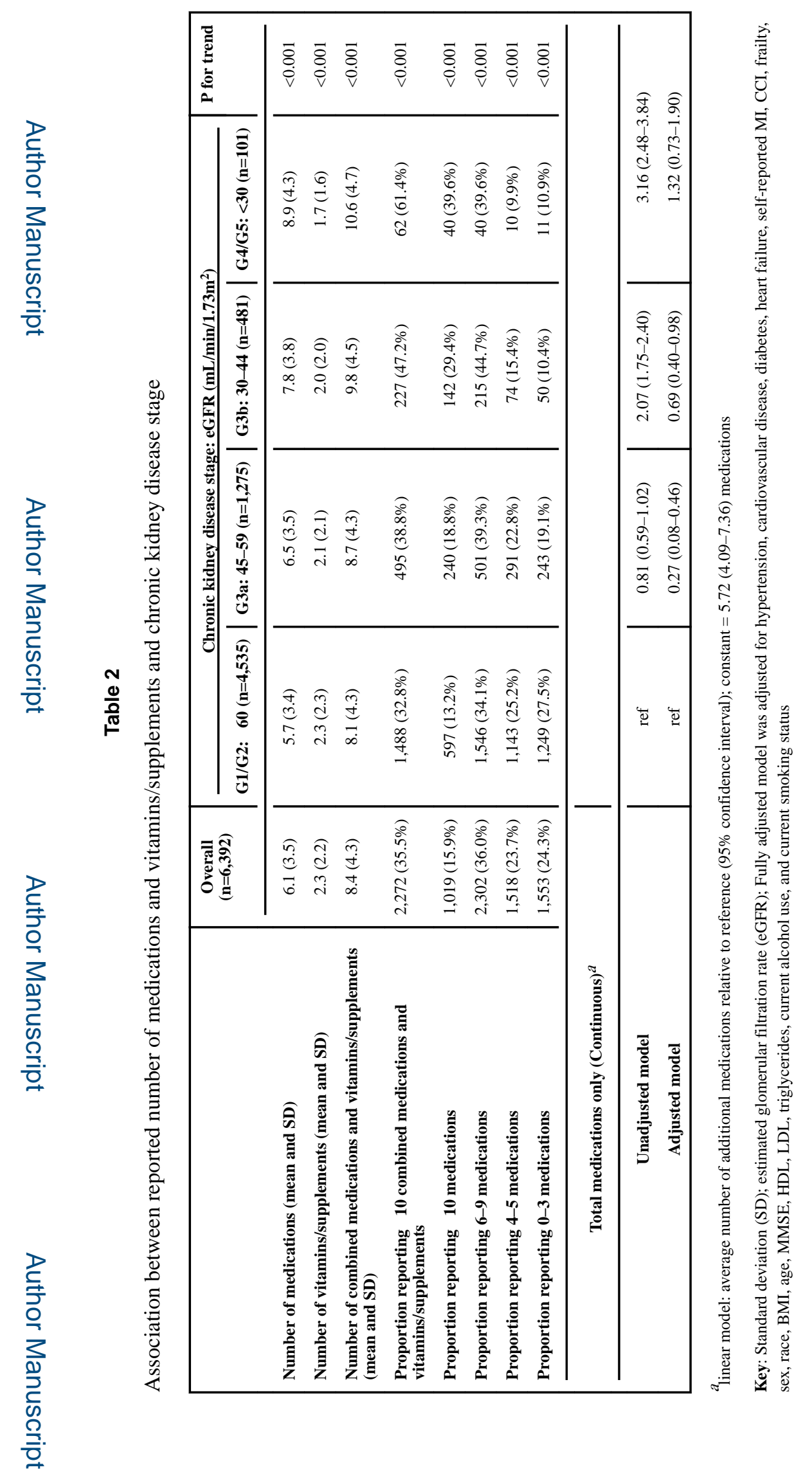

Drugs Aging. Author manuscript; available in PMC 2019 August 01. 


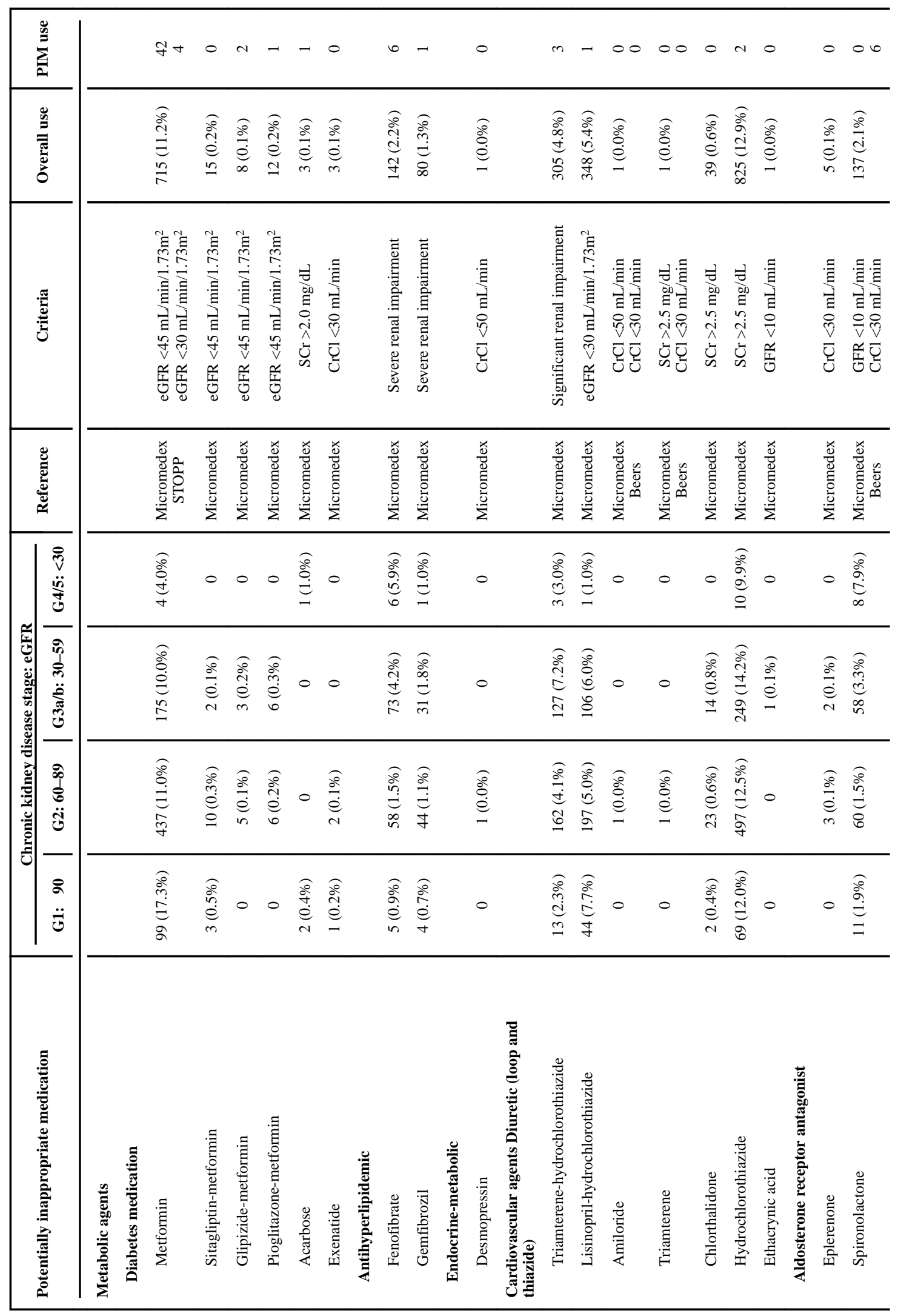

Drugs Aging. Author manuscript; available in PMC 2019 August 01. 


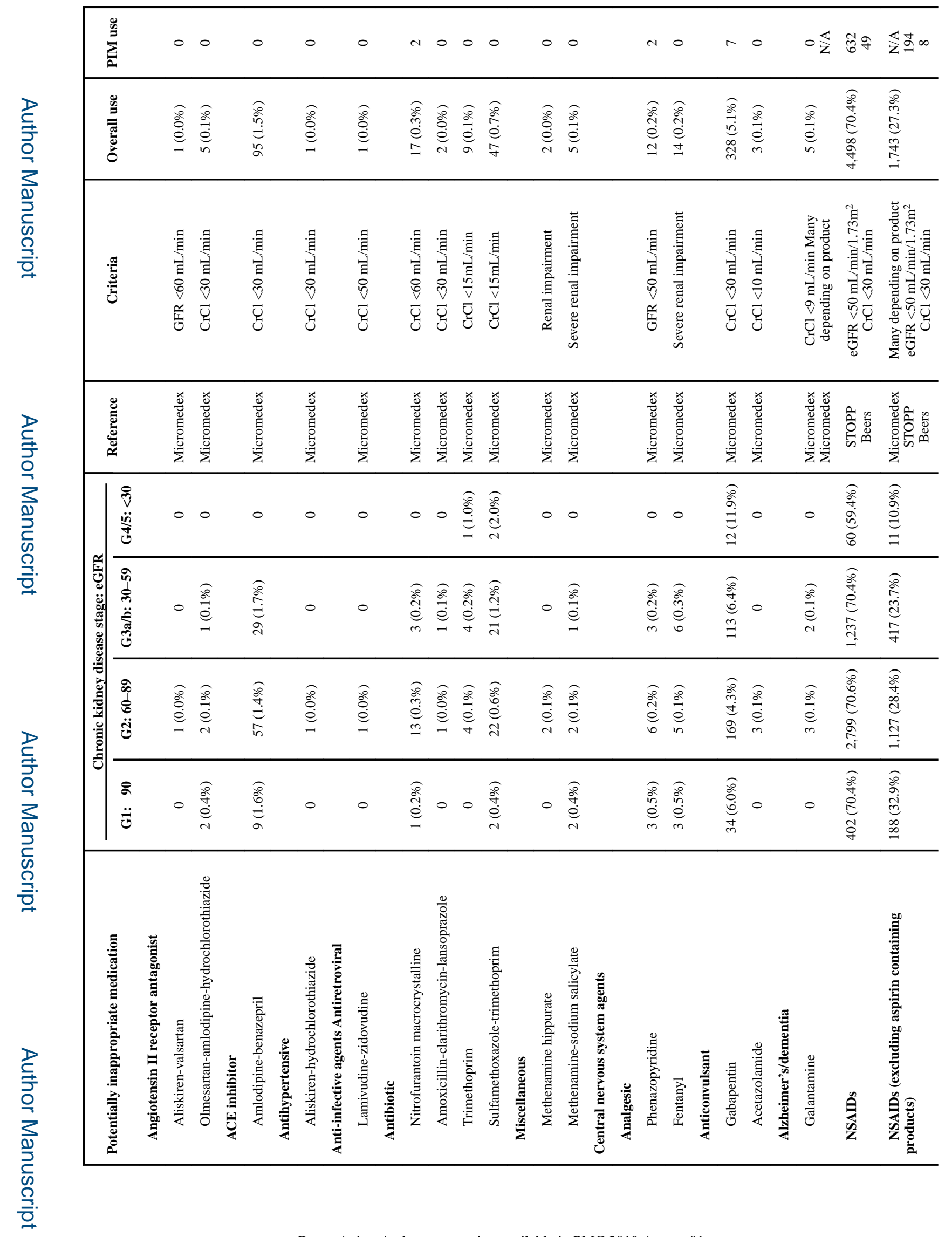

Drugs Aging. Author manuscript; available in PMC 2019 August 01. 


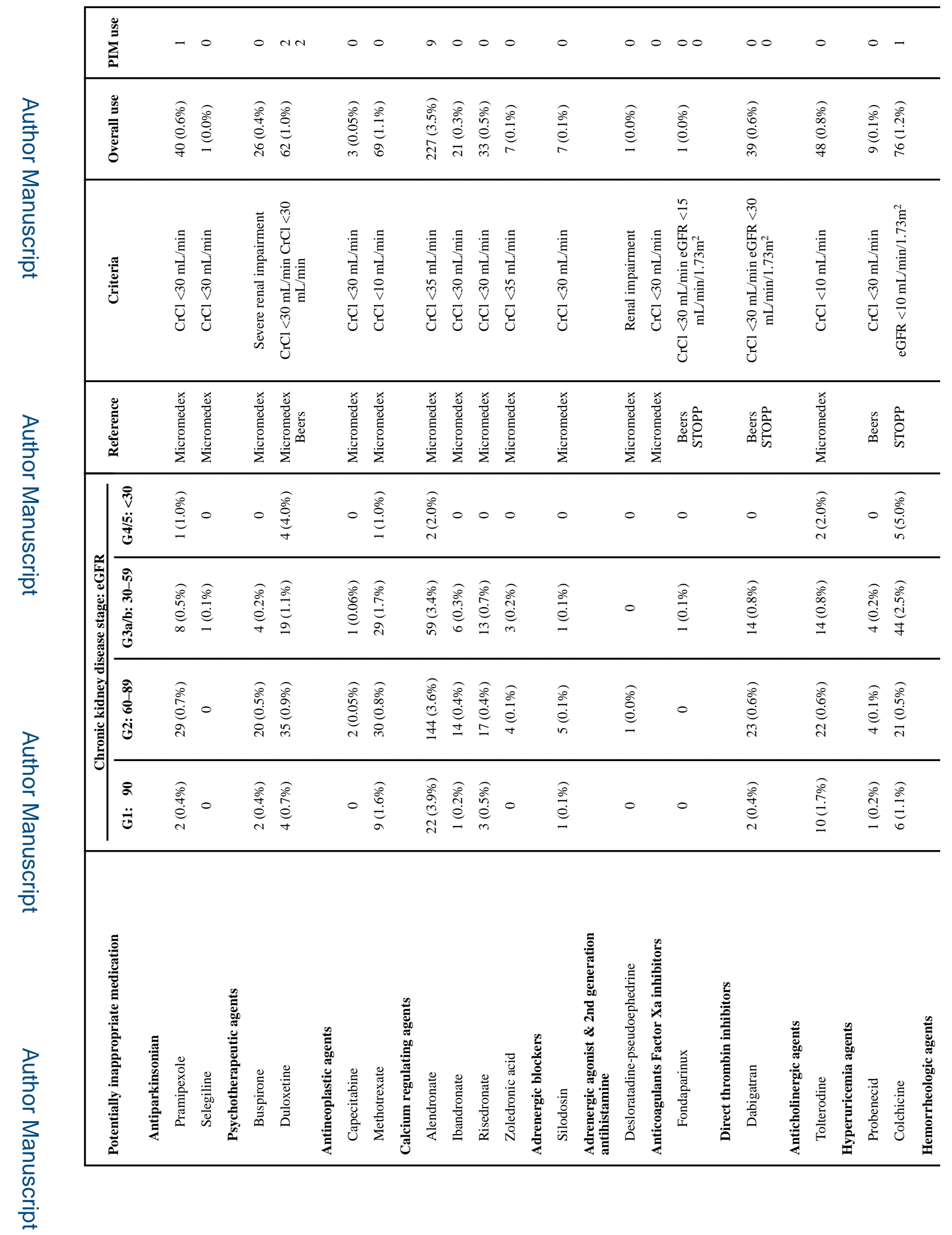

Drugs Aging. Author manuscript; available in PMC 2019 August 01. 


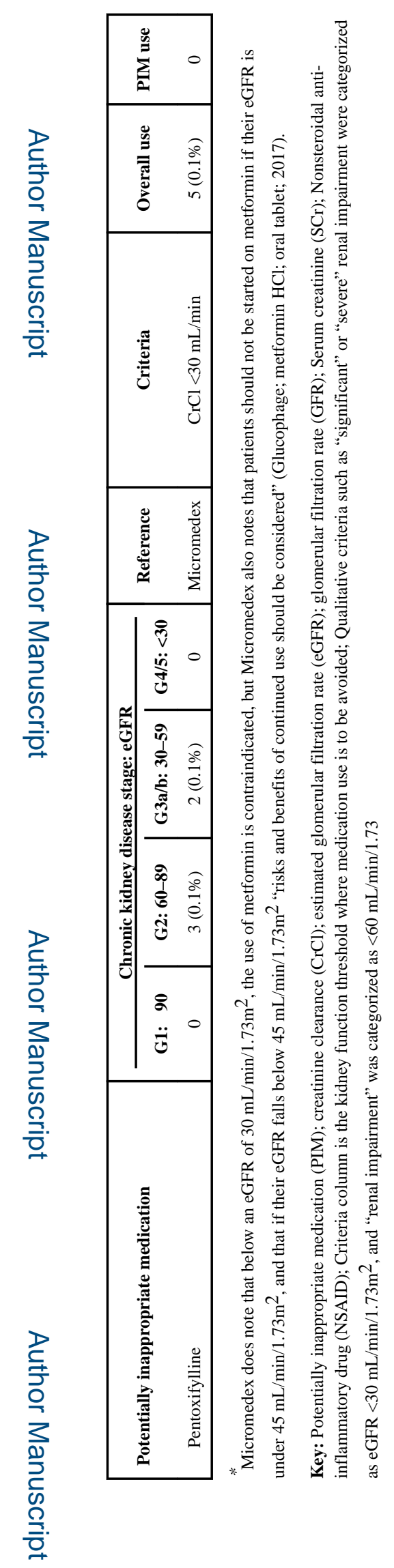

Drugs Aging. Author manuscript; available in PMC 2019 August 01. 


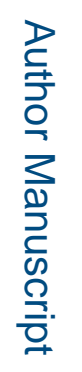

\begin{tabular}{|c|c|c|c|c|c|c|c|c|c|c|c|c|c|c|c|c|c|c|c|c|c|c|}
\hline \multirow{4}{*}{ 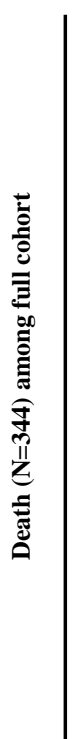 } & \multirow{4}{*}{ 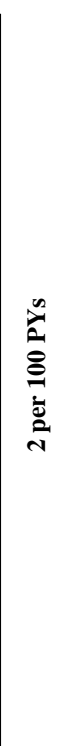 } & 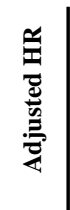 & 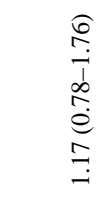 & 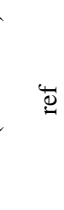 & 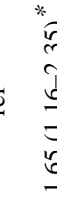 & 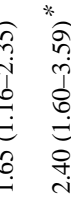 & & 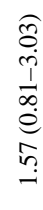 & 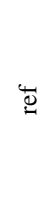 & 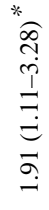 & 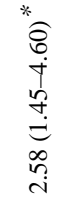 & $\stackrel{\sigma}{-}$ & $\begin{array}{l}\infty \\
0 \\
\\
\\
0\end{array}$ & & 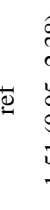 & 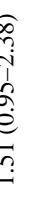 & 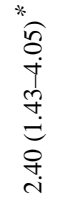 & & & 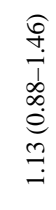 & & 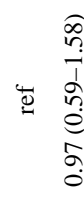 \\
\hline & & 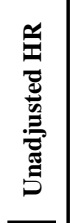 & 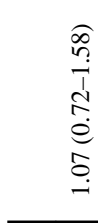 & 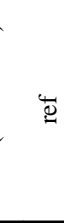 & 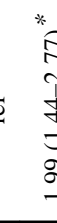 & 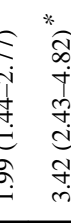 & & 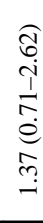 & 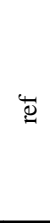 & 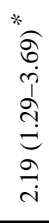 & 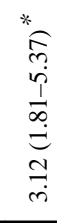 & 。 & $\frac{0}{0}$ & & 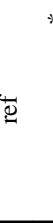 & 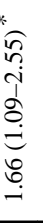 & 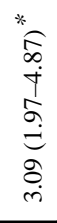 & & 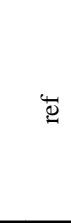 & 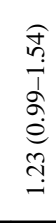 & & 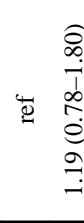 \\
\hline & & 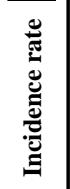 & 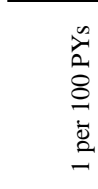 & 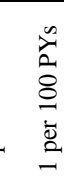 & 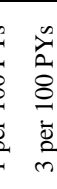 & 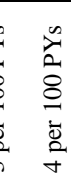 & & 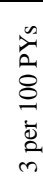 & 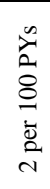 & 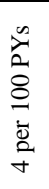 & 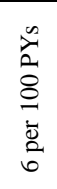 & $\begin{array}{l}\frac{8}{8} \\
\stackrel{\bar{\Xi}}{-}\end{array}$ & 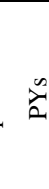 & & 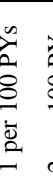 & 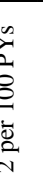 & $\begin{array}{l}\frac{n}{\Delta} \\
\frac{0}{0} \\
\frac{\bar{\Xi}}{m}\end{array}$ & & 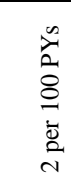 & 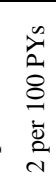 & & 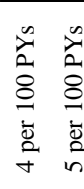 \\
\hline & & 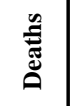 & in & $\stackrel{\infty}{a}$ & 王 & $\widehat{\varrho}$ & & নి & $=$ & 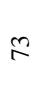 & in & $m$ & & & $\bar{m}$ & 8 & f & & సิ & $\bar{\Xi}$ & & $\stackrel{\sigma}{\sigma} \infty$ \\
\hline \multirow{4}{*}{ 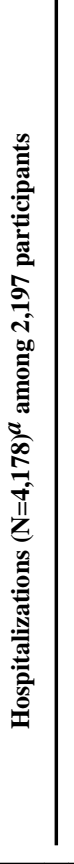 } & \multirow{4}{*}{ 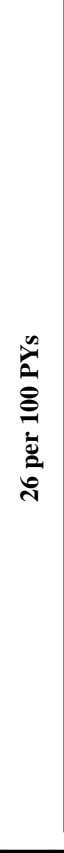 } & 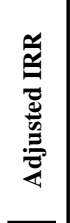 & 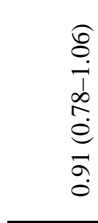 & 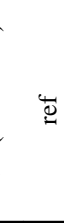 & 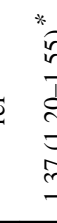 & 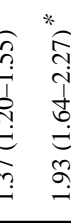 & & $\begin{array}{l}\widehat{\approx} \\
\stackrel{n}{t} \\
\infty \\
\stackrel{0}{0} \\
\stackrel{m}{=}\end{array}$ & 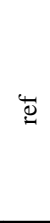 & 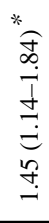 & 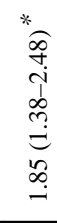 & $\infty$ & $\frac{\widehat{\sigma}}{\frac{1}{1}}$ & & 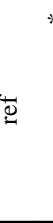 & 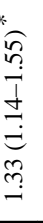 & 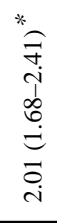 & & 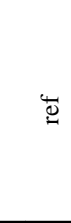 & 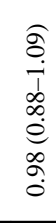 & & 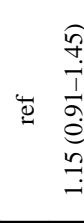 \\
\hline & & 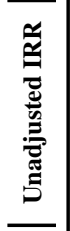 & $\begin{array}{l}* \\
\text { ลे } \\
0 \\
0 \\
0 \\
0 \\
0 \\
0 \\
0 \\
0\end{array}$ & $\overbrace{0}^{\infty}$ & $\begin{array}{l}* \\
0 \\
5 \\
5 \\
5\end{array}$ & 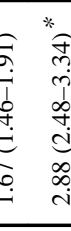 & & 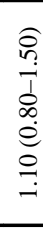 & $\stackrel{\square}{\square}$ & 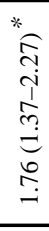 & 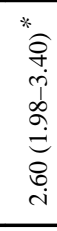 & $\stackrel{\infty}{\stackrel{0}{0}}$ & * & & 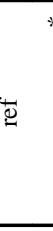 & & 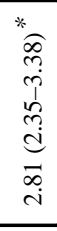 & & $\Psi$ & 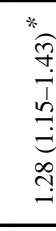 & & $\stackrel{\breve{\Xi}}{\breve{\Xi}}$ \\
\hline & & 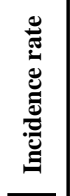 & 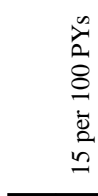 & 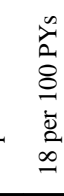 & 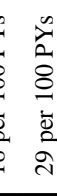 & 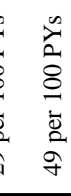 & & 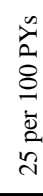 & 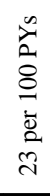 & 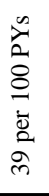 & 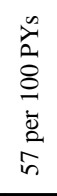 & $\begin{array}{l}8 \\
\bar{\Xi} \\
\text { ळे }\end{array}$ & ఓ & & 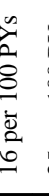 & 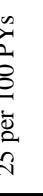 & 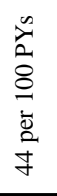 & & 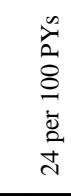 & 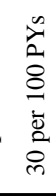 & & 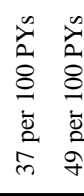 \\
\hline & & 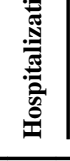 & s. & $\stackrel{尺}{尺}$ & : & ڤ્ત & & $\stackrel{\infty}{\infty}$ & $\stackrel{t}{N}$ & $\stackrel{2}{2}$ & $\stackrel{\infty}{n}^{\circ}$ & $\stackrel{\partial}{7}$ & & & $\begin{array}{l}\infty \\
\stackrel{\infty}{+} \\
\stackrel{\circ}{a}\end{array}$ & हे & f & & 芯 & $\stackrel{n}{n}$ & & $\stackrel{2}{n}$ \\
\hline & 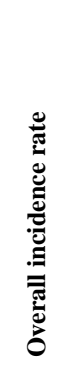 & & 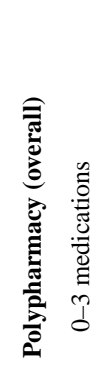 & 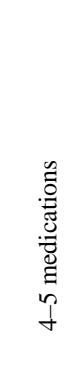 & 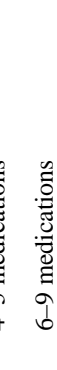 & 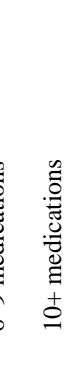 & 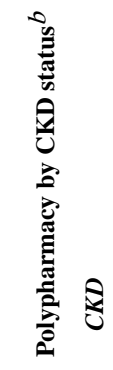 & 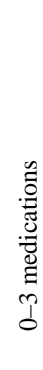 & 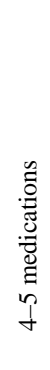 & 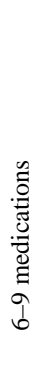 & 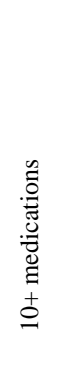 & $\begin{array}{l}8 \\
8 \\
z\end{array}$ & 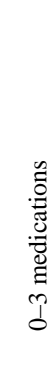 & & 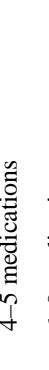 & bَ & 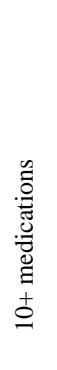 & 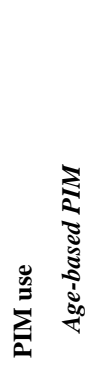 & 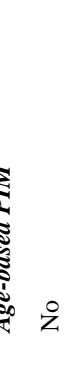 & . & 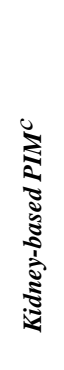 & ¿ : \\
\hline
\end{tabular}

Drugs Aging. Author manuscript; available in PMC 2019 August 01. 


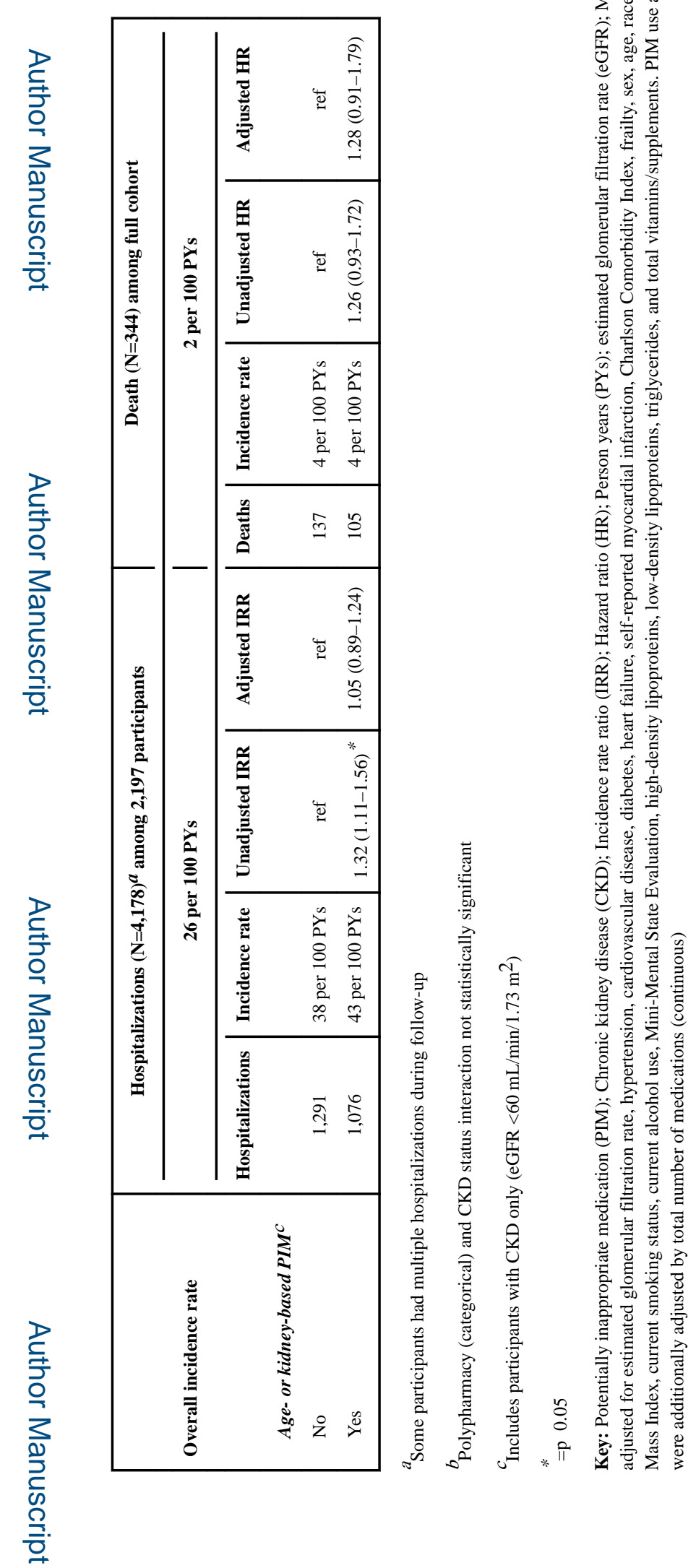

Drugs Aging. Author manuscript; available in PMC 2019 August 01. 